\title{
Meta-analysis of the parasitic phase traits of Haemonchus contortus infection in sheep

Mathilde Saccareau ${ }^{1 *}$, Guillaume Sallé ${ }^{2}$, Christèle Robert-Granié ${ }^{1}$, Tom Duchemin $^{1}$, Philippe Jacquiet ${ }^{3,4}$, Alexandra Blanchard ${ }^{2}$, Jacques Cabaret ${ }^{2}$ and Carole R. Moreno ${ }^{1}$

\begin{abstract}
Background: The parasitic nematode Haemonchus contortus shows highly variable life history traits. This highlights the need to have an average estimate and a quantification of the variation around it to calibrate epidemiological models.

Methods: This paper aimed to quantify the main life history traits of H. contortus and to identify explanatory factors affecting these traits using a powerful method based on a systematic review and meta-analysis of current literature. The life history traits considered are: (i) the establishment rate of ingested larvae; (ii) the adult mortality rate; (iii) the fertility (i.e. the number of eggs laid/female/day); and (iv) fecundity of female worms (i.e. the number of eggs per gram of faeces).

Results: A total of 37 papers that report single experimental infection with $\mathrm{H}$. contortus in sheep and published from 1960 to 2015, were reviewed and collated in this meta-analysis. This encompassed 115 experiments on 982 animals. Each trait was analysed using a linear model weighted by its inverse variance. The average ( \pm SE) larval establishment rate was $0.24 \pm 0.02$, which decreased as a function of the infection dose and host age. An average adult mortality rate of $0.021 \pm 0.002$ ) was estimated from the literature. This trait varied as a function of animal age, breed and protective response due to prior exposure to the parasite. Average female fertility was $1295.9 \pm 280.4$ eggs/female/day and decreased in resistant breeds and previously infected hosts. Average faecal egg count at necropsy was $908.5 \pm 487.1$ eggs per gram of faeces and varied as a function of infection duration and host resistance. The average sex ratio of $\mathrm{H}$. contortus was $0.51 \pm 0.006$.

Conclusion: This work is the first systematic review to summarise the available information on the parasitic phase of $\mathrm{H}$. contortus in sheep. The results of the meta-analysis provide robust estimates of life history traits for parametrization of epidemiological models, their expected variation according to experimental factors, and provides correlations between these.
\end{abstract}

Keywords: Haemonchus contortus, Gastro-intestinal nematode, Sheep, Meta-analysis, Resistance, Female fertility, Larval establishment, Adult mortality, Sex ratio

\section{Background}

The blood-feeding nematode Haemonchus contortus is one of the most pathogenic parasites in sheep [1]. The wide geographic distribution and increasing resistance against anthelmintic control measures has made this species a leading threat to the sustainability of sheep industries in Oceania, warm-humid regions [2] and Europe [3].

\footnotetext{
* Correspondence: mathilde.saccareau@gmail.com

'INRA - INPT-ENSAT - INPT-ENVT - Université de Toulouse, UMR 1388

GenPhySE, Castanet Tolosan, France

Full list of author information is available at the end of the article
}

The critical impact on livestock production combined with the relative ease of producing parasite material in the laboratory have made this species a primary model of interest. For instance, specific genomic resources have been built to elucidate the genetic architecture of drug resistance mechanisms [4] and this species has also been used to evaluate alternative control strategies such as selective breeding for resistance to infection [5]. The success of these research avenues relies heavily upon the population dynamics and biology of $H$. contortus that both influence the diffusion of drug resistance alleles [6]. 
Mathematical models of parasite life-cycles provide an effective tool to advance epidemiological understanding $[7,8]$ and aid decision-making in parasite control strategies [9-12]. Indeed, the in silico approach allows for multiple scenarios to be considered without having to resort to experimentation once the model was validated [13-15]. These mechanistic models rely on the input of specific parameters, such as life history traits of the parasitic phase. Robust and average values for these traits are lacking, despite an extensive body of literature available on the subject. Recent systematic reviews and meta-analyses have been published to build knowledge of these parameters in other important gastrointestinal parasites such as Cooperia oncophora and Ostertagia ostertagi [16, 17] and Teladorsagia circumcincta [18]. Yet, despite the comprehensive literature available tackling the life-cycle of $H$. contortus [1], including both the free-living (eggs to infective larvae) and parasitic stages (infective larvae to reproductive adult worms), a quantitative assessment of $H$. contortus population dynamics and ecology is still missing.

The aim of this paper was to conduct a systematic review and meta-analysis of data collected on experimentally infected sheep with $H$. contortus, published before 2016, using the same methodology as Verschave et al. [16]. The main life history traits selected for study in the parasitic phase of $H$. contortus included: (i) larval establishment; (ii) adult mortality; (iii) female fertility and population level fecundity. To obtain robust estimates of the life history traits, several experimental variation factors were considered i.e. infection dose, duration of the infection, host age, genetic background of host resistance and previous exposure to $H$. contortus.

\section{Methods}

Verschave et al. [16] performed the systematic review and meta-analysis of Ostertagia ostertagi life traits in bovines. In this paper, the same approach was used for Haemonchus contortus life history traits. However papers reporting trickle infection results were removed as overlapping worm generations obscure worm age and thus prevent reliable estimation of larval establishment and adult mortality rates. Additional explanatory factors were studied, i.e. the influence of host resistance and of a previous exposure to $H$. contortus before the studied experiment. Some variance equations used in Verschave et al. [16] were corrected in this paper (Additional file 1: Text).

\section{Searching strategy and eligibility criteria}

An exhaustive data collection was performed using the Web of Sciences database (https://www.webofknowledge. com) using the following keywords: ((gastrointestinal AND nematode) or (gastrointestinal AND parasite*) OR haemonchus OR contortus)) AND (infect* OR pathogen* OR mortality OR establishment OR fecundity) AND (sheep OR lamb* OR ewe* OR wether* OR ram* OR $\left.\operatorname{dam}^{*}\right)$. Selection of the papers used in the present study was completed on January $7^{\text {th }}, 2016$.

In the first review phase, papers were selected based on title compatibility. Papers without full text accessibility, unavailable through library services or published in languages other than French or English were discarded. Finally, the eligibility of the remaining papers was decided following a full reading of the text to meet the following criteria: (i) natural infections were excluded due to unknown parasite exposure; (ii) experiments which used anthelmintic treatments prior to sheep slaughter were not considered; and (iii) papers reporting their results graphically i.e. without precise values were removed.

In the second review phase, additional selection criteria were applied to the papers based on experimental design conditions. Insufficiently detailed experiments (i.e. the time between infection and slaughter) or nutritional supplementation studies (e.g. protein, zinc, selenium, papaya latex, condensed tannins) were withdrawn. Studies based on trickle infection protocols were also discarded, as larval stages from consequent infections will overlap with adult stages from the initial challenge making it impossible to correctly estimate larval establishment and adult mortality rates, particularly for infections of long duration. To ensure a robust meta-analysis, only experiments reporting the arithmetic means and associated measures of variance (standard deviation or standard error of the mean) for worm burden were kept for further analysis. Studies lacking experimental power (less than 3 animals) were ignored. Finally, the data were weighed according to their associated variances during estimation procedures. As atypical behaviour of variances were obtained for underpowered experiments (less than 10 animals), experiments showing too large or too small worm burden variance estimate (i.e. two standard deviations from the mean associated variance) were discarded.

\section{Parameter definition and specific eligibility criteria}

The life history traits of $H$. contortus considered were: larval establishment which was estimated as the proportion of ingested larvae retrieved at necropsy, irrespective of the developmental stage (i.e. $L_{4}$, immature stages, adult worms), the adult mortality rate (i.e. the proportion of adult worms that die per day), the female fertility and the population level fecundity. As defined by Southwood [19], fertility corresponds to the individual capacity of a female to lay eggs (measured by the total daily egg output in sheep faeces divided by the total number of female worms), whereas fecundity corresponds to the capacity of 
a population to lay eggs (measured by the total daily egg output in faeces). For each considered life history trait, the equations used to calculate mean estimates and their associated variances are summarised in Table 1 and detailed in Additional file 1: Text.

To disentangle larval establishment rate from adult mortality rate, we assumed according to expert knowledge that no adult worms die before 30 days postinfection (dpi), hence estimating larval establishment rate from experiments lasting less than 30 days and adult mortality rate from longer experiments. The worm's sex ratio was estimated from experiments reporting separately female and male worm numbers. The number of female worms was assumed by this sex ratio estimation when unknown. Daily faeces production (DFP, g/day) was estimated as a direct function of host body weight (BW, kg) [20]:

$$
\operatorname{DFP}(g / \text { day })=0.041 * 1000 * B W^{0.75}
$$

Body weight that was missing in one paper [21] using Texel sheep was inferred from the paper of Freetly et al. [22] who derived a function linking body weight and age in Texel sheep.

The general study description (country, year, number of sheep), sheep-host details (breed, gender, age, body weight, previous exposure to $H$. contortus), $H$. contortus details (isolate, drug resistance status, infection dose) and experimental conditions (infection duration, concomitant infection with other nematode species) were included in our database. Host resistance to gastrointestinal nematodes was inferred from the literature, where Barbados Black Belly, Saint Croix, Florida Native [23], Santa Ines [24, 25], Canaria hair breed [26] and divergent selection lines were considered resistant breeds. Two $H$. contortus isolates were included: anthelmintic resistant (thiabendazole-resistant strain) or $H$. contortus isolates (ISE isolates) obtained after serial passages in resistant hosts.

\section{Meta-analysis}

Statistical analyses were performed using $\mathrm{R}$ version 3.1.3. [27]. The life history trait estimates and their associated variances were calculated for each experiment of our final database (Table 1). Each life history trait estimate was analysed using a linear fixed model (stats package) weighted by the inverse of their associated variance. The considered explanatory variables were the host age (in months), the host resistance (i.e. susceptible, resistant, unknown status), the infection dose (i.e. the number of $\mathrm{L}_{3}$ inoculated per animal), the infection duration (i.e. number of days post-infection), previous exposure to $H$. contortus (i.e. immunologically naïve, natural preinfection assumed, experimental pre-infection). Due to the skewed distribution of the life history traits, they were studied with, and without, a log transformation in further analyses. Quantitative explanatory variables (i.e. host age, infection dose and duration of infection) were clustered into balanced classes as the hypothesis of linearity between life history traits and explanatory variables was rejected.

First, a backward variable selection was implemented based on AIC criterion [28]. Then, only factors with a $P$-value $<0.05$ were kept in the final models. F-tests were calculated to select significant factors using the car $\mathrm{R}$ package [29]. The estimation of means for each level of factors was performed using the lsmeans $\mathrm{R}$ package [30].

As each life history trait had a different inverse variance weight, it was impossible to use the same criteria to weight the correlation between life history traits. Consequently, correlations between life history traits were weighted by the number of sheep involved in the experiment using the 'weight' $R$ package [31].

\section{Results}

Figure 1 provides a description of the paper selection steps and the associated selection criteria. A total of 9480 references were retrieved from Web of Sciences that were narrowed down to 383 following title-based selection. The first review phase of the papers led to a selection of 81 eligible publications, reduced with the second review phase to 37 papers that estimate at least one $H$. contortus life history trait [21, 32-67]. This final database (see Additional file 2) comprised a total of 982 animals used in 115 different experiments (using different

Table 1 Mean estimate and associated variance of the main life history traits of $H$. contortus

\begin{tabular}{lllll}
\hline & Larval establishment (E) & Adult mortality $(\mu)$ & Female fertility $(F)$ & Population level fecundity $(f)$ \\
\hline Definition & $\begin{array}{l}\text { Proportion of ingested larvae } \\
\text { that develop into immature }\end{array}$ & $\begin{array}{l}\text { Proportion of adult worms } \\
\text { that die per day }\end{array}$ & $\begin{array}{l}\text { Mean number of eggs laid in } \\
\text { sheep faeces by an adult female } \\
\text { per adult worms }\end{array}$ & $\begin{array}{l}\text { Mean number of eggs counted } \\
\text { per gram of faeces }\end{array}$ \\
Mean estimate & $\frac{W B}{I D}$ & $\frac{-\ln \left(\frac{W B}{D}\right)}{t}$ & $\frac{F E C_{n} * D F P}{W B * F_{p}}$ & $F E C_{n}$ \\
Variance & $\frac{S E(W B)^{2}}{I D^{2}}$ & $\frac{S E(W B)^{2}}{(t * W B)^{2}}$ & $\frac{D F P^{2}}{F_{p}^{2}} * \frac{F E C_{n}{ }^{2}}{W B^{2}} *\left(\frac{S E\left(F E C_{n}\right)^{2}}{F E C_{n}^{2}}+\frac{S E(W B)^{2}}{W B^{2}}\right)$ & $S E\left(F E C_{n}\right)$ \\
\hline
\end{tabular}

Abbreviations: WB Worm burden, ID Infection dose, $t$ days after infection, $F E C_{n}$ Faecal egg count at necropsy, DFP Daily faeces production, $F_{p}$, proportion of female worms, SE Standard error 


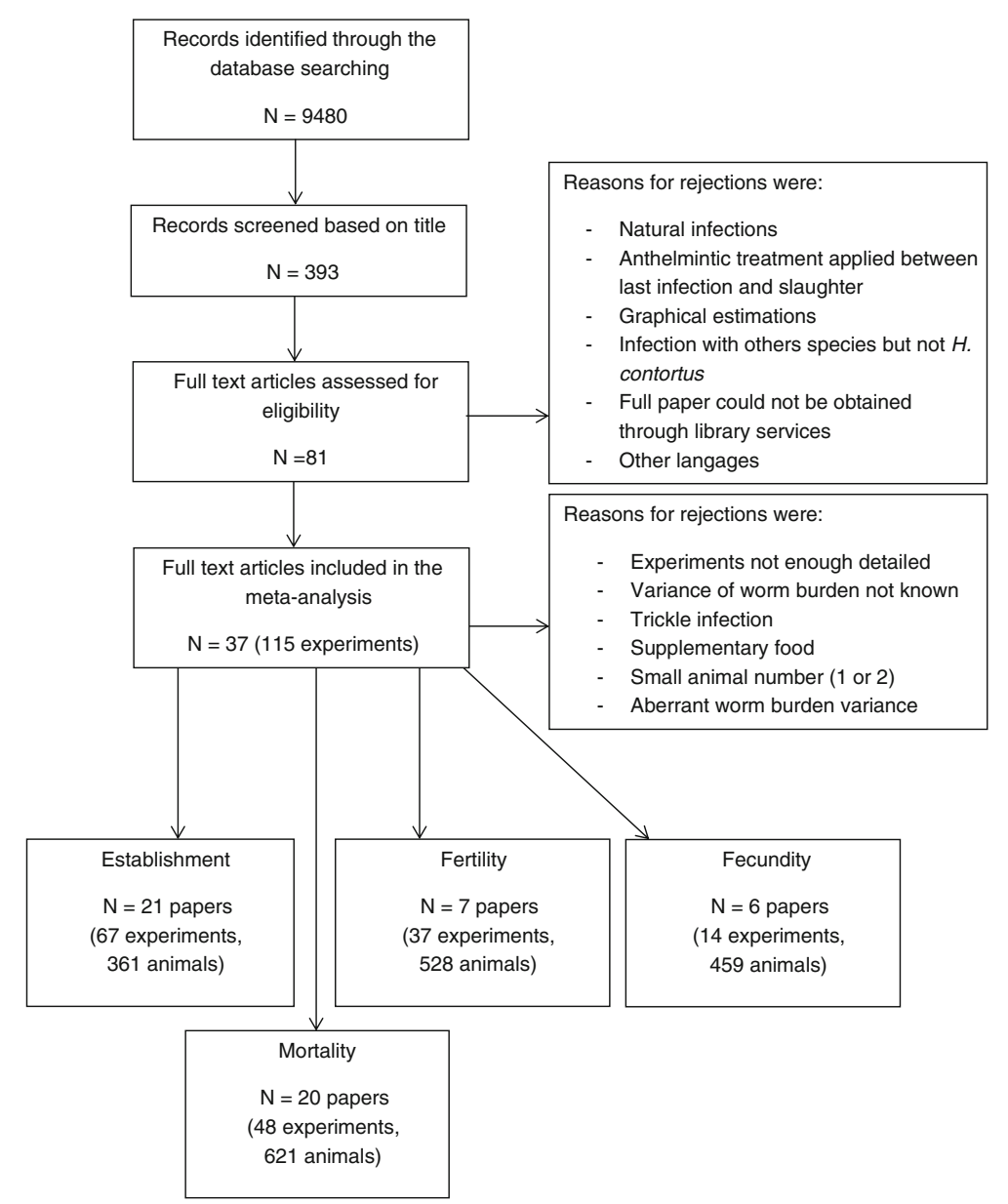

Fig. 1 Diagram of the paper selection from the database Web of Science and associated eligibility criteria

experimental conditions as the duration of infection and/or the infection dose).

Table 2 summarizes the details and available life history traits for each paper kept in the final database and the distribution of the experiment number over the different explanatory factors is shown in Additional file 3: Table S1.

In addition, the proportion of female worms was estimated from 28 experiments that indicated female and male worm numbers separately. The mean $( \pm$ standard error, SE) proportion of female worms was $0.51 \pm 0.006$, which corresponds to a female: male sex ratio of 1.04:1. Estimates for other life history traits of the parasitic phase of $H$. contortus are provided in Table 3.

\section{Larval establishment rate}

Average larval establishment rate was $0.24 \pm 0.02$. The final model, including all the significant explanatory factors, explained $49.5 \%$ of total variance (Table 3).
The $H$. contortus establishment rate peaked between 10 and 19 dpi (Fig. 2a). Larval establishment rate significantly decreased with the size of the infection dose from 10,000 to $20,000 \mathrm{~L}_{3}$ (Fig. 2b), but was highest for the greatest infection dose (result not significant). A reduced proportion of larvae reached adult stages in older hosts (Fig. 2c). This result was consistently obtained, with or without experiments using older sheep than usual age, i.e. 36-month-old $v s 7$ months on average for remaining studies (results not shown).

In our meta-analysis, the proportion of immature stages significantly decreased after $20 \mathrm{dpi}$ and almost disappeared after $40 \mathrm{dpi}$ (Additional file 4: Figure S1), except within a few underpowered experiments from the same paper [47] performed at 49 and $70 \mathrm{dpi}$.

\section{Adult mortality rate}

The average $( \pm$ SE) daily per capita adult mortality rate was $0.021 \pm 0.002$, resulting in a mean life expectancy $(1 /$ mortality rate) of 50 days. The proportion of worms surviving (worm burden/infection dose) with 


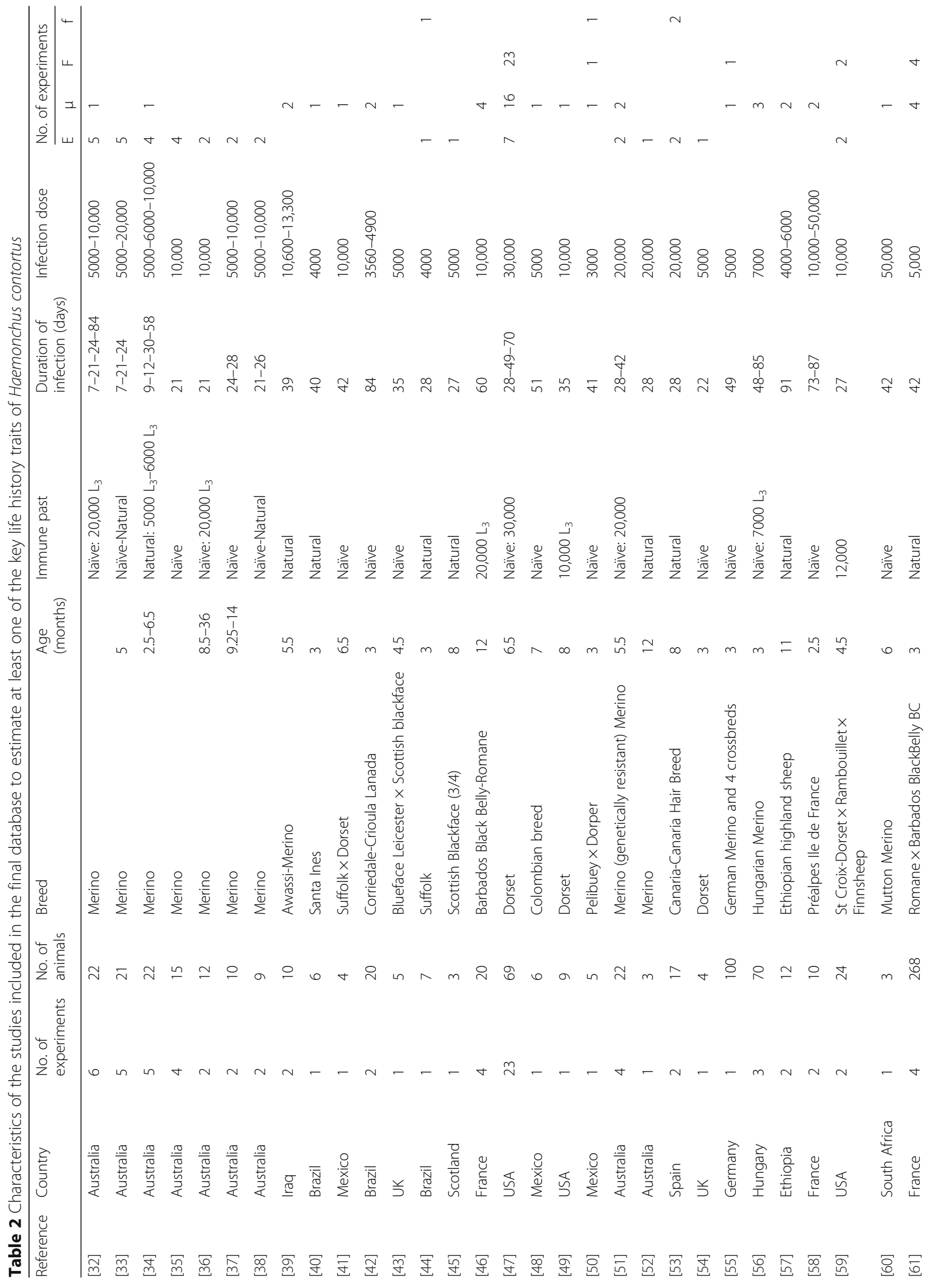




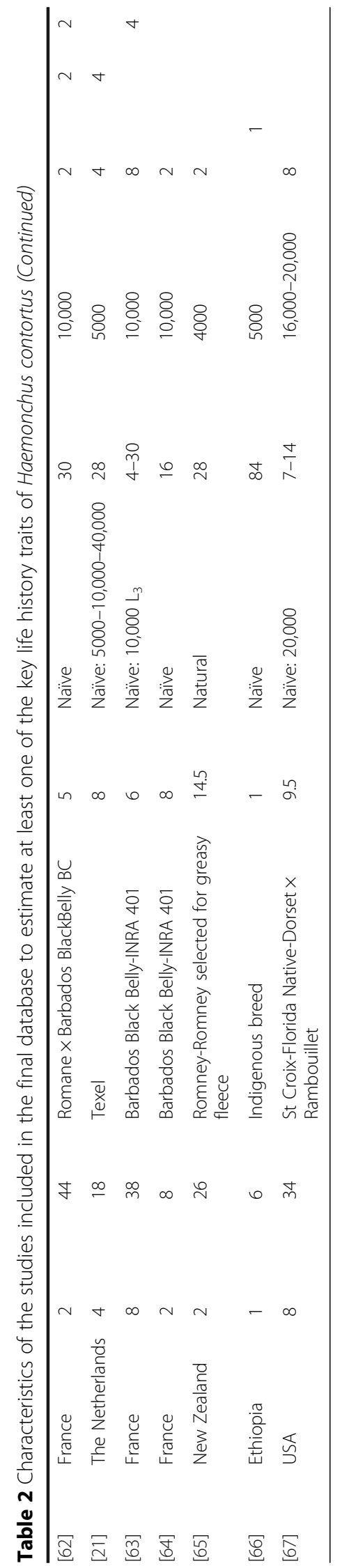


Table 3 The results of the final linear models to estimate each life history trait of the parasitic phase of $H$. contortus

\begin{tabular}{llll}
\hline Life history traits $\quad$ Explanatory factors & Estimation of means $S E$
\end{tabular}

Larval establishment rate (proportion of ingested larvae that develop into immature or adult worms)

Infection duration

$$
\begin{aligned}
& \text { 4-9 dpi } \\
& 12-16 \mathrm{dpi} \\
& 21-30 \mathrm{dpi}
\end{aligned}
$$

Infection dose

$$
\begin{aligned}
& 4000-5000 L_{3} \\
& 10,000 L_{3} \\
& 16,000-20,000 L_{3} \\
& 30,000 L_{3}
\end{aligned}
$$

SE

$\begin{array}{ll}0.09 & 0.08 \\ 0.27 & 0.05 \\ 0.23 & 0.03\end{array}$

Host age

$$
\begin{aligned}
& \text { 2.5-5 months } \\
& \text { 5.5-10 months } \\
& 12-36 \text { months }
\end{aligned}
$$

Adult mortality rate (Proportion of adult worms that die per day)

Host GIN resistance status

0.003

Susceptible
Resistant
Unknwon

0.039

0.009

0.065

0.011

0.048

0.009

Isolate status

$$
\begin{aligned}
& \text { Susceptible to anthelmintics or non-adapted to sheep } \\
& \text { resistance isolate of } H \text {. contortus } \\
& \text { Isolate adapted to sheep resistance }{ }^{\text {a }} \\
& \text { Isolate resistant to anthelmintics } \\
& \text { Unknown }
\end{aligned}
$$

0.044

0.005

Host age

$$
\begin{aligned}
& 1.2-3 \text { months } \\
& 4.5-8 \text { months } \\
& 11-12 \text { months }
\end{aligned}
$$

0.044

0.009

0.069

0.033

0.062

0.012

0.026

0.003

0.045

0.005

Previous host exposure

chas

Immunologically naive

Suspected natural pre-infection

Experimental abbreviated pre-infection

0.059

0.009

0.010

0.047

0.009

0.049

$<0.001$

0.039

0.009

0.063

0.010

0.009

Female fertility (number of eggs/female/day)

Host GIN resistance status

$$
\begin{aligned}
& \text { Susceptible } \\
& \text { Resistant } \\
& \text { Unknown }
\end{aligned}
$$

Infection duration

$$
\begin{aligned}
& 27-30 \text { dpi } \\
& 41-50 \text { dpi } \\
& 70 \text { dpi }
\end{aligned}
$$$$
2136.5
$$$$
2270.6
$$$$
6344.7
$$$$
<0.001
$$$$
513.1
$$ 
Table 3 The results of the final linear models to estimate each life history trait of the parasitic phase of H. contortus (Continued)

Previous exposure of host

$$
\begin{aligned}
& \text { Immunologically naive host } \\
& \text { Experimental pre-infection }
\end{aligned}
$$

Population level fecundity (number of eggs/gram of faeces) ${ }^{b}$

Susceptible

Resistant

Unknown

Infection duration

$\begin{array}{rr}13536.8 & 1429.1 \\ 4837.4 & 918.8 \\ 9563.8 & 992.7\end{array}$

1034.9

2575.9

415.6

ay serial passages in resistant host

${ }^{\mathrm{b}}$ The host age was not included in the models for this trait due to a limited dataset Abbreviation: SE standard error

time was plotted for every experiment (Fig. 3). As expected, an exponential decrease of the survival probability was observed. The explanatory factors selected as significant in the final model (Table 3) explained $64.6 \%$ of the heterogeneity in adult mortality. Strong discrepancies in study's contribution were observed (Fig. 4).

Significant variations in adult mortality rates were observed according to the $H$. contortus isolate used in the experiment. Susceptible isolates had a significantly higher adult mortality rate than isolates with an unknown resistance. Although not significant, anthelmintic resistant isolates (thiabendazole-resistant strain) demonstrated higher estimated adult mortality rates, and isolates resistant to the immune response had the highest adult mortality rate estimate.

Other explanatory factors were host resistance $\left(F_{(2,37)}=\right.$ 6.82, $P=0.003)$, previous exposure of the host to $H$. contortus $\left(F_{(2,37)}=11.385, P<0.001\right)$ and host age $\left(F_{(2,37)}=6.039\right.$, $P=0.005)$. Resistant sheep and sheep previously infected with $H$. contortus experimentally eliminated worm burdens faster than their susceptible and immunologically naive
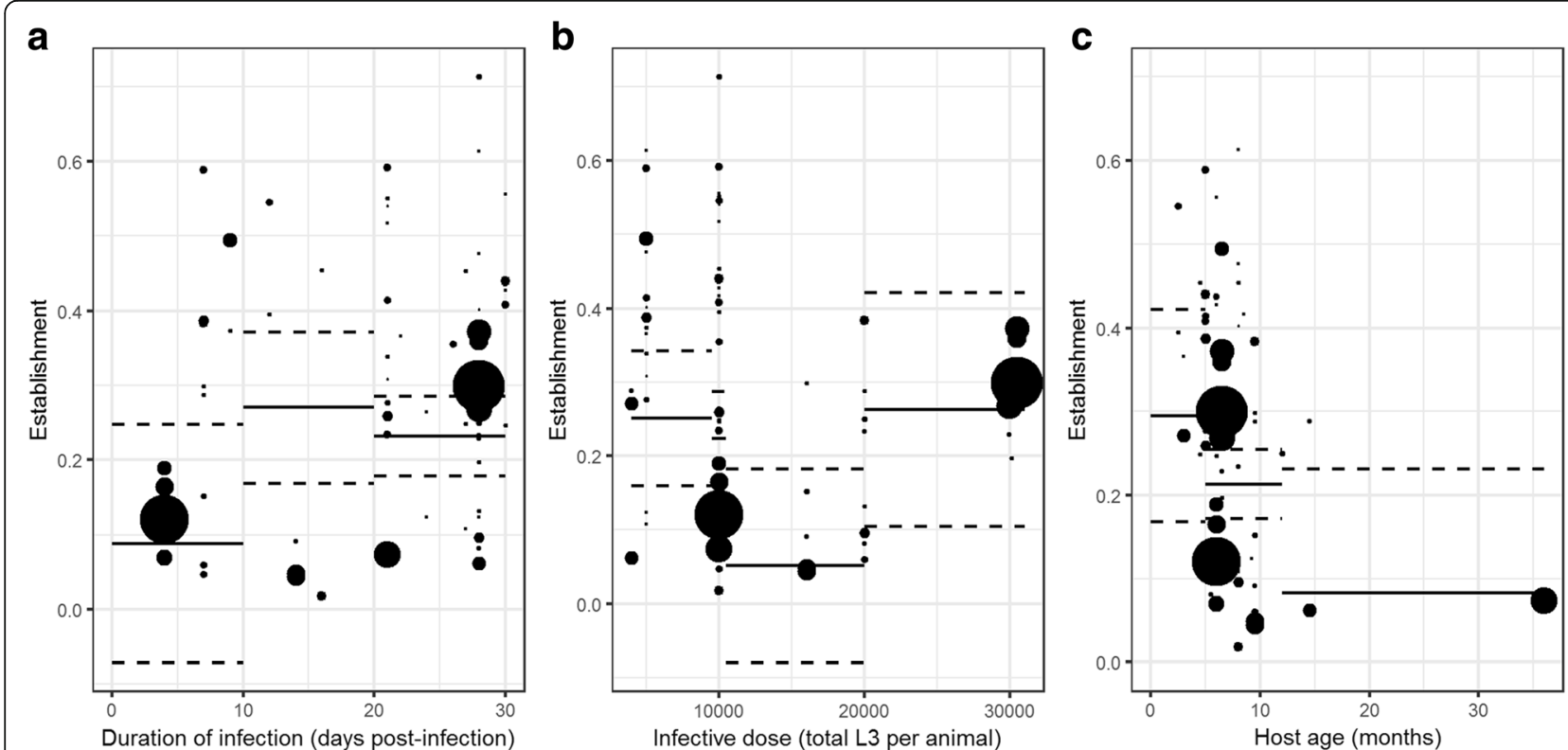

Fig. 2 Estimations of the larval establishment according to the slaughter date after infection $\mathbf{a}$, the infection dose $\mathbf{b}$ and the host age $\mathbf{c}$. Point size represents the weight associated to each experiment. The solid black lines represent the estimations in the final models and their associated confidence intervals (dashed lines) 


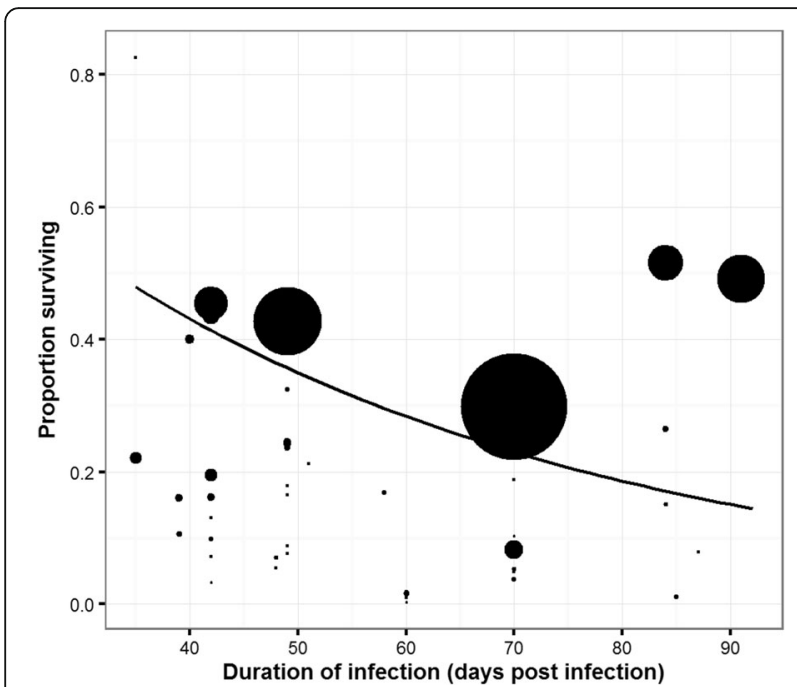

Fig. 3 Proportion of surviving worms (i.e. worm burden/infection dose) according to the time post-infection. Point size represents the weight associated to each experiment. The line is based on the average of the adult mortality rate $(\mu)$ with the adult mortality equation $(\exp (-\mu t)$, where $t$ is the number of days post-infection)

counterparts. Adult mortality rates increased with host age (except for individuals aged from 8 to 12 months old, result not significant). In this class, two experiments were highweighted and decreased the adult mortality rate estimation by erasing the trend of the other experiments.

\section{Female fertility and fecundity}

The average $( \pm$ SE) female fertility was $1295.9 \pm 280.4$ eggs per female worm per day. It was strongly associated

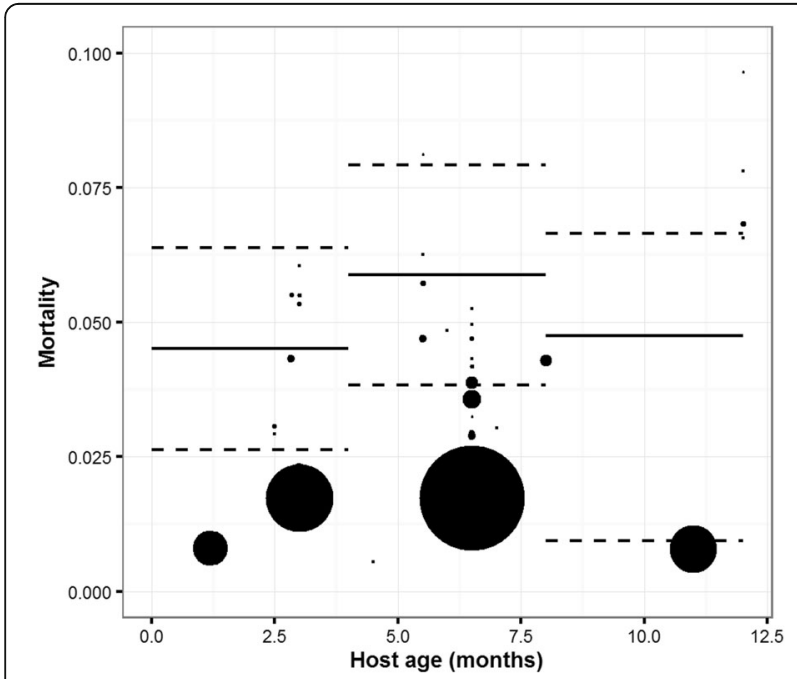

Fig. 4 Estimations of the adult mortality according the host age. Point size represents the weight associated to each experiment. The solid black lines represent the estimations in the final models and their associated confidence intervals (dashed lines) with the duration of infection $\left(F_{(2,31)}=12.343, P<0.001\right)$ : female fertility increased with the duration of infection (Fig. 5). Female fertility was less in previously challenged hosts and in resistant breeds compared to their immunologically naive counterparts and susceptible breeds. The explanatory factors considered in the model explained $85.11 \%$ of the heterogeneity.

The average faecal egg count at necropsy was 908.5 \pm 487.1 eggs per gram of faeces. This fecundity was also affected by the host resistance status $\left(F_{(2,9)}=\right.$ 72.341, $P<0.001)$ and by the duration of infection $\left(F_{(2,9)}=13.171, P=0.002\right)$. Fecundity strongly decreased from $30 \mathrm{dpi}$ (Additional file 5: Figure S2) whereas the female fertility continued to increase until $70 \mathrm{dpi}$ (Fig. 5).

\section{Phenotypic correlations between life history traits}

As shown on Table 4, the adult mortality rate was negatively correlated with female fertility $\left(r_{(22)}=-0.49, P<\right.$ $0.05)$. Sex ratio was significantly correlated with all other life history traits: negatively correlated with both larval establishment rate $\left(r_{(12)}=-0.77, P<0.01\right)$ and female worm fertility $\left(r_{(5)}=-0.9, P<0.05\right)$ and positively correlated with adult mortality rate $\left(r_{(12)}=0.69, P<0.05\right)$.

\section{Discussion}

To our knowledge, this meta-analysis is the first to collect and summarize the available information on the main life history traits of the parasitic phase of $H$. contortus. The quantification of each parameter, associated with a variation, provides a good foundation to calibrate

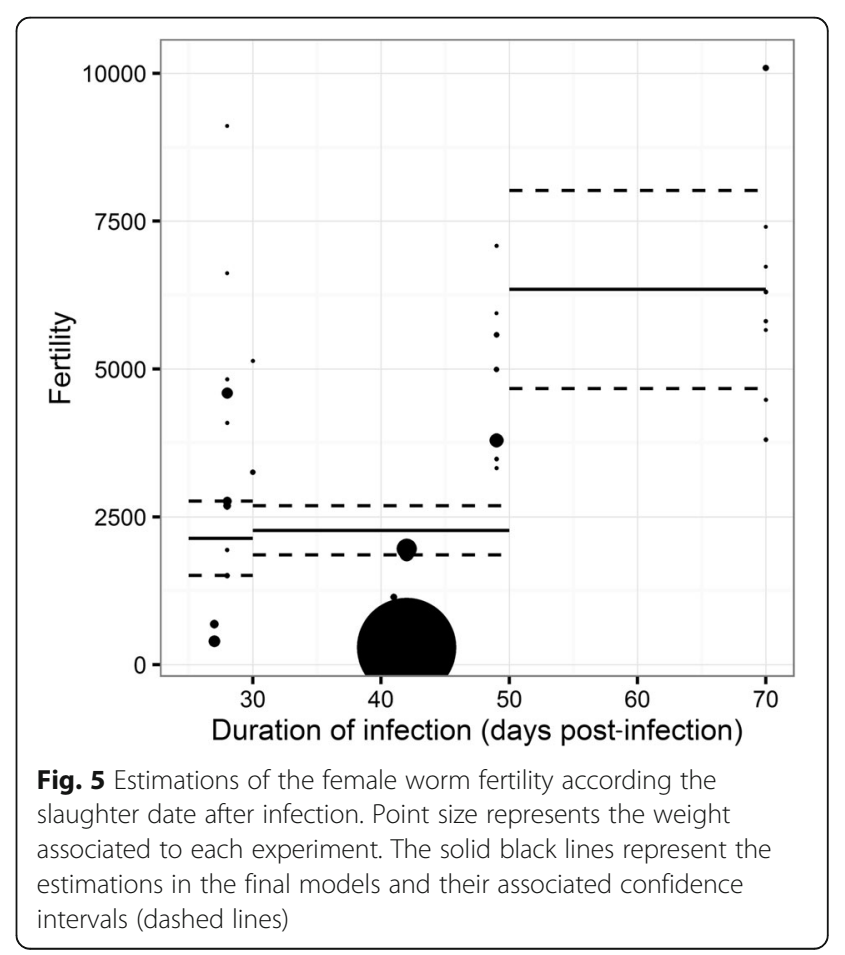


Table 4 Pearson's correlation coefficients between the life history traits of the parasitic phase of H. contortus (weighted by the number of animals in the experiment)

\begin{tabular}{|c|c|c|c|c|c|}
\hline & Larval establishment rate (E) & Adult mortality rate $(\mu)$ & Female fertility (F) & Population level fecundity ( $f$ ) & Sex ratio \\
\hline$E$ & & ne & -0.07 & 0.39 & $-0.77^{* *}$ \\
\hline$\mu$ & & & $-0.49^{*}$ & $-0.88^{*}$ & $0.69^{*}$ \\
\hline $\mathrm{F}$ & & & & $0.58^{*}$ & $-0.9^{*}$ \\
\hline$f$ & & & & & -0.86 \\
\hline Sex ratio & & & & & \\
\hline
\end{tabular}

${ }^{*} P<0.05 ;{ }^{* *} P<0.01$

Abbreviation: ne No estimate (less than two experiments)

future epidemiological models describing the parasitic phase of $H$. contortus.

To ensure the quality of our estimates, several criteria were integrated. First, we selected papers giving arithmetic means and variance for two traits: worm burden and faecal egg counts. For the few papers, which gave individual measurements for these two traits, aggregated values were calculated (arithmetic mean and variance). This conservative strategy allowed for increased information from a greater number of studies to be included. This is in contrast to a similar meta-analysis carried out for $T$. circumcincta, which only considered individual worm burden measurements [18]. Like many parametric tests, the analysis of variance assumed the data were normally distributed. However, the traits studied here were non-normal and presented a skewed distribution. Fortunately, the ANOVA test is not very sensitive to moderate deviations from normality; simulation studies, using a variety of non-normal distributions have shown that the false positive rate is not much affected by not adhering to this assumption [68]. In our case, a logtransformation was applied to normalize the life history traits; the results were the same with and without this transformation confirming the robustness of ANOVA. Secondly, using the inverse variance of each life history trait to weight the mean estimate is the most robust way to analyse data reported as a mean with measurement standard deviation and animal number [69]. Studies which only reported means (without the associated measure of variance) or graphical values had to be excluded from further analysis.

Larval establishment and adult mortality are two interwoven traits. Indeed, while most larval stages will evolve into mature adults within 15 days [70], delays can occur that result in larval recovery for up to 30 days after infection [63]. To provide the best larval establishment rate estimates, i.e. the total proportion of infective larvae reaching the adult stage, worm count data up to $30 \mathrm{dpi}$ were considered. Usually, $H$. contortus egg output increases between this stage of infection and $30 \mathrm{dpi}$ as seen in longitudinal faecal egg count sampling (Additional file 5: Figure S2), suggesting that either female worm fertility increases, or that the total number of mature adult stages increases, or both. Therefore, we considered that adult mortality between 15 and 30 dpi was negligible and not to be taken into account. To calculate the number of female worms, a sex ratio of 0.5 was assumed in the material and methods and the present meta-analysis corroborates this sex ratio. This value is a slightly lower than estimations from another meta-analysis which considered several nematode species simultaneously [71].

The success of the nematode in terms of fitness, based on the ability to establish and to produce offspring, relies on both parasite density-dependent constraints and host immune response [72]. Density-dependent stunting of female fertility has been reported for various parasitic species like $H$. contortus in sheep [73], O. ostertagi in cattle [16], Trichostrongylus retortaeformis in rabbits [72], Strongyloides robustus in squirrels [74] or Syngamus trachea in crows [75]. From our data, the infection dose did not significantly impact $H$. contortus female fertility, nor its adult mortality rate, but it affected the larval establishment rate. This unexpected result may be explained by the homogenous and relatively small infection doses used in our database to estimate female fertility and adult mortality which were mainly between $5000 \mathrm{~L}_{3}$ and $10,000 \mathrm{~L}_{3}$ and thus lower than the $10,000 \mathrm{~L}_{3}$ threshold where a density dependence effect is generally expected [73]. The only experiments with an infection dose of $30,000 \mathrm{~L}_{3}$ used a small sample size (three animals) leading to highly variable estimations. In addition, all these experiments came from the same paper ([47]) with specific environmental conditions (i.e. parasite strain, sheep breed, body weight, sheep sex). In natural infections, the cumulative level of infection is probably lower than $10,000 \mathrm{~L}_{3}$ larvae (J. Cabaret, personal communication). The results gathered in our study have confirmed the negative impact of the host immune status on both $H$. contortus fertility and mortality, as reported for other trichostrongylid species [76]. These findings tend to favor a negative effect of steric crowding on larval establishment. It remains unresolved whether the observed effects on $H$. contortus mortality and 
fertility were due to direct host responses, or from density-dependent effects mediated by the host immune response as demonstrated in Strongyloides ratti infections [77]. Further, the infection dose is only an indirect approximation of the actual established worm burden so that density dependence may be overlooked.

The negative impact of host genetic resistance on $H$. contortus mortality rate and female fertility corroborates previous results comparing resistant and susceptible breeds $[78,79]$ or lines of sheep with divergent resistance status $[62,80]$. Such an observation also links with the proposed framework for the immune response against $T$. circumcincta [81].

Surprisingly, naturally pre-challenged sheep seemed to exert a significantly lighter response on adult mortality rate than their experimentally pre-challenged or naïve counterparts. This may be a result of the misclassification of studies due to a lack of information in the material and methods section. For example, some experimental animals were explicitly mentioned as naturally infected (even if pasture infectivity was not stated) and treated to remove presence of parasites, but some others were mentioned as receiving preventative treatments but not really faced parasite challenge.

Haemonchus contortus is well known as one of the most prolific sheep parasite [82]. Our estimates indicate a high female fertility of $1295.9 \pm 280.4 \mathrm{eggs} / \mathrm{fe}-$ male/day on average, which outperforms other trichostrongylids [82]. It is usually postulated that this high female fertility will result in a huge population size showing a high degree of genetic variability [83]. However, our estimates also suggest that larval establishment constitutes a strong bottleneck as only a quarter of the ingested larvae will have an opportunity to mate and pass on their genetic material to subsequent generations. This may constrain the expected population size of $H$. contortus.

The mean estimated life expectancy of 50 days by this meta-analysis underestimated the predicted half-life of an established worm burden of 69 days as described by Barger \& Le Jambre [84]. Indeed, the equation used to estimate the adult mortality rate [47] did not take into account the establishment of the ingested larvae (assumed as 100\%) leading to an overestimation of the adult mortality rate. The analyses were also made with the equation of Barger \& Le Jambre [84] using the average larval establishment rate estimated by our meta-analysis. Unfortunately, for a third of the experiments this estimate is higher than the effective larval establishment rate of the experiment, leading to a negative adult mortality rate (replaced by 0 in this case) and thus biasing the adult mortality estimates.

Interestingly, the more female-biased the $H$. contortus population was, the lower the establishment and fertility rates were, yet with higher adult mortality rates. These correlations are difficult to interpret as the higher proportion of females could be a cause, or a consequence, of the two other traits. Female worms are thought to live longer than males, which could explain why populations exhibiting high adult mortality rate also show more females than males [71]. The higher proportion of females in low larval establishment rates may be a result of a better female survival capacity. The decrease in female fertility observed for female-biased populations may be due to either a competition for males, or competition for resources as their nutrient requirements are usually higher than for males [71].

\section{Conclusions}

To our knowledge, this comprehensive systematic review of the parasitic phase of $H$. contortus is the first to summarize these extensive data and to provide average overall life history trait estimates. These informative estimations are very helpful to parameterize epidemiological transmission models more accurately. This meta-analysis also gives evidence for density dependence of larval establishment, for host age affecting larval establishment and adult mortality and shows that an improved immune response, induced by the resistance status of the breed or by a previous exposure to the parasites, affects adult mortality and female fertility. An improved understanding of the parasitic life-cycle will allow us to evaluate the impact of different control strategies on parasitic infection with an increased confidence in the output predictions of dynamic models. For example, the sustainability of treatments and genetic selection strategies could be evaluated both on the infection level of the flock and on the increase of resistant alleles in parasite strains. The impact of environmental factors on free living stages also lacks precise estimates and a meta-analysis of these would certainly help to conclude on this point.

\section{Additional files}

Additional file 1: Text: Calculation method to estimate the variance of each life history trait. (DOCX $30 \mathrm{~kb}$ )

Additional file 2. Data: Final database of all the papers included in the meta-analysis after all the selection criteria. (XLSX $33.4 \mathrm{~kb}$ )

Additional file 3: Table S1. Distribution of the experiment number, of the animal number and of the experiment weight over different levels of the explanatory factors. (DOCX $17 \mathrm{~kb}$ )

Additional file 4: Figure S1. Proportion of immature stages on the total worm burden according to the infection duration post infection. Point size represents the weight associated to each experiment. The solid black line represents the fitting by polynomial model (degree 2) and the dashed lines represent its confidence interval. (TIFF 2774 kb)

Additional file 5: Figure S2. Faecal egg count according to the infection duration post infection. Black cross sizes represent the weight associated to each faecal egg count reported. Grey crosses represent faecal egg count reported without the associated measure of variance. (TIFF $2600 \mathrm{~kb}$ ) 


\section{Abbreviations}

DFP: Daily faeces production; FEC: Faecal egg count; FEC : Faecal egg count at necropsy; $F_{p}$ : Proportion of female worms; ID: Infection dose; SE: Standard error; WB: Worm Burden.

\section{Acknowledgments}

We are grateful to Dr Caroline Chylinski for helpful comments on the manuscript.

\section{Funding}

This project was funded by the INRA program GISA. M. Saccareau receives a grant from the INRA Animal Health and Animal Genetics departments.

\section{Availability of data and materials}

The data supporting the conclusions of this article are included within the article and its additional files.

\section{Authors' contributions}

MS performed literature review, statistical analysis and the main redaction of the paper. CM and CR-G participated to the choice of statistical methods. All other co-authors participated to the interpretations of results, discussions and corrections of the redaction. All authors read and approved the final manuscript.

\section{Competing interests}

The authors declare that they have no competing interests.

\section{Consent for publication}

Not applicable.

\section{Ethics approval and consent to participate}

Not applicable.

\section{Publisher's Note}

Springer Nature remains neutral with regard to jurisdictional claims in published maps and institutional affiliations.

\section{Author details}

INRA - INPT-ENSAT - INPT-ENVT - Université de Toulouse, UMR 1388 GenPhySE, Castanet Tolosan, France. ${ }^{2}$ INRA - Université de Tours, UMR 1282 ISP, 37380, Nouzilly, France. ${ }^{3}$ INRA - INPT-ENVT - Université de Toulouse, UMR 1225 IHAP, Toulouse, France. ${ }^{4}$ INRA - INPT-ENVT, UMT Santé des petits ruminants, Centre de recherche de Toulouse, Toulouse, France.

\section{Received: 23 September 2016 Accepted: 5 April 2017}

Published online: 24 April 2017

\section{References}

1. Besier RB, Kahn LP, Sargison ND, Van Wyk JA. Chapter Four-The pathophysiology, ecology and epidemiology of Haemonchus contortus infection in small ruminants. Adv Parasitol. 2016;93:95-143.

2. Kaplan RM, Vidyashankar AN. An inconvenient truth: global worming and anthelmintic resistance. Vet Parasitol. 2012;186:70-8.

3. Blake N, Coles G. Flock cull due to anthelmintic-resistant nematodes. Vet Rec. 2007:161:36-36

4. Laing R, Kikuchi T, Martinelli A, Tsai IJ, Beech RN, Redman E, et al The genome and transcriptome of Haemonchus contortus, a key model parasite for drug and vaccine discovery. Genome Biol. 2013;14:1-16.

5. Bishop SC, Morris CA. Genetics of disease resistance in sheep and goats. Small Rumin Res. 2007;70:48-59.

6. Cornelius MP, Jacobson C, Dobson R, Besier RB. Computer modelling of anthelmintic resistance and worm control outcomes for refugia-based nematode control strategies in Merino ewes in Western Australia. Vet Parasitol. 2016:220:59-66.

7. Callinan APL, Morley FHW, Arundel JH, White DH. A model of the life cycle of sheep nematodes and the epidemiology of nematodiasis in sheep. Agric Syst. 1982;9:199-225.

8. Barger IA. Genetic resistance of hosts and its influence on epidemiology. Vet Parasitol. 1989:32:21-35. Spec. Issue 13th WAAVP Conf.

9. Saccareau M, Moreno CR, Kyriazakis I, Faivre R, Bishop SC. Modelling gastrointestinal parasitism infection in a sheep flock over two reproductive seasons: in silico exploration and sensitivity analysis. Parasitology. 2016;143: 1509-31.

10. Learmount J, Taylor MA, Smith G, Morgan C. A computer model to simulate control of parasitic gastroenteritis in sheep on UK farms. Vet Parasitol. 2006; 142:312-29.

11. Barnes EH, Dobson RJ, Barger IA. Worm control and anthelmintic resistance: adventures with a model. Parasitol Today. 1995;11:56-63.

12. Leathwick DM, Vlassoff A, Barlow ND. A model for nematodiasis in New Zealand lambs: The effect of drenching regime and grazing management on the development of anthelmintic resistance. Int J Parasitol. 1995;25: 1479-90.

13. Laurenson YCSM, Kyriazakis I, Forbes AB, Bishop SC. Exploration of the epidemiological consequences of resistance to gastro-intestinal parasitism and grazing management of sheep through a mathematical model. Vet Parasitol. 2012:189:238-49.

14. Laurenson YCSM, Kyriazakis I, Bishop SC. In silico exploration of the impact of pasture larvae contamination and anthelmintic treatment on genetic parameter estimates for parasite resistance in grazing sheep. J Anim Sci. 2012:90:2167-80.

15. Vagenas D, Doeschl-Wilson A, Bishop SC, Kyriazakis I. In silico exploration of the effects of host genotype and nutrition on the genetic parameters of lambs challenged with gastrointestinal parasites. Int J Parasitol. 2007;37: 1617-30.

16. Verschave SH, Vercruysse J, Claerebout E, Rose H, Morgan ER, Charlier J. The parasitic phase of Ostertagia ostertagi: quantification of the main life history traits through systematic review and meta-analysis. Int J Parasitol. 2014:44:1091-104

17. Verschave SH, Rose H, Morgan ER, Claerebout E, Vercruysse J, Charlier J. Modelling Cooperia oncophora: Quantification of key parameters in the parasitic phase. Vet Parasitol. 2016:223:111-4.

18. Gaba S, Gruner L, Cabaret J. The establishment rate of a sheep nematode: Revisiting classics using a meta-analysis of 87 experiments. Vet Parasitol. 2006;140:302-11.

19. Southwood TRE. Observational and experimental methods for the estimation of natality, mortality and dispersal. In: Southwood TRE, editor Ecological methods: With Particular Reference to the Study of Insect Populations. Netherlands: Springer; 1978. p. 302-55.

20. Cabaret J, Ouhelli, H. La fertilite des strongles digestifs lors de l'infestation naturelle des brebis. Rev Med Vet. 1984;135:627-33.

21. Schallig HDF, van der Aar W, Boersema J, Cornelissen AWC. The effect of oxfendazole terminated infections with Haemonchus contortus on the development of immunity in sheep. Vet Parasitol. 2000:88:61-72

22. Freetly HC, Nienaber JA, Leymaster KA, Jenkins TG. Relationships among heat production, body weight, and age in Suffolk and Texel ewes. J Anim Sci. 1995;73:1030-7.

23. Bishop SC. Possibilities to breed for resistance to nematode parasite infections in small ruminants in tropical production systems. Animal. 2012:6:741-7.

24. Amarante AFT, Susin I, Rocha RA, Silva MB, Mendes CQ, Pires AV. Resistance of Santa Ines and crossbred ewes to naturally acquired gastrointestinal nematode infections. Vet Parasitol. 2009;165:273-80.

25. do Amarante A, Bricarello PA, Rocha RA, Gennari SM. Resistance of Santa Ines, Suffolk and lle de France sheep to naturally acquired gastrointestinal nematode infections. Vet Parasitol. 2004;120:91-106.

26. Guo Z, González JF, Hernandez JN, McNeilly TN, Corripio-Miyar Y, Frew $D$, et al. Possible mechanisms of host resistance to Haemonchus contortus infection in sheep breeds native to the Canary Islands. Sci Rep. 2016;6:26200.

27. R: A Language and Environment for Statistical Computing. Vienna: $R$ Core Team; 2014. Available from: http://www.R-project.org/. Accessed 10 Apr 2017.

28. Ripley B, Venables B, Bates DM, Hornik K, Gebhardt A, Firth D, et al Package "MASS." CRAN Repos. Httpcran R-Proj. OrgwebpackagesMASSMASS Pdf. 2013

29. Fox J, Weisberg S, Adler D, Bates D, Baud-Bovy G, Ellison S, et al. Package "car". 2016. https://cran.r-project.org/package=car. Accessed 10 Apr 2017.

30. Lenth R. Least-Squares means: The R Package Ismeans. J Stat Softw. 2016; doi:10.18637/jss.V069.101

31. Pasek J. Package "weights". 2016. https://cran.r-project.org/package=weights. Accessed 10 Apr 2017 
32. Adams DB. Time of onset and target of immune reactions in sheep with acquired immunity against Haemonchus contortus. Int J Parasitol. 1982;12:439-43.

33. Adams DB. Investigation with dexamethasone of the processes which moderate immunity against the nematode, Haemonchus contortus, in sheep. Aust J Exp Biol Med Sci. 1983;61:345-53.

34. Adams DB. Observations on the self-cure reaction and other forms of immunological responsiveness against Haemonchus contortus in sheep. Int J Parasitol. 1983;13:571-8.

35. Adams DB. Developmental arrest of Haemonchus contortus in sheep treated with a corticosteroid. Int J Parasitol. 1986;16:659-64.

36. Adams DB. The effect of dexamethasone on a single and a superimposed infection with Haemonchus contortus in sheep. Int J Parasitol. 1988;18:575-9.

37. Adams DB. A preliminary evaluation of factors affecting an experimental system for vaccination-and-challenge with Haemonchus contortus in sheep. Int J Parasitol. 1989;19:169-75.

38. Adams DB, Davies HI. Enhanced resistance to infection with Haemonchus contortus in sheep treated with a corticosteroid. Int J Parasitol. 1982;12:523-9.

39. Khshali MN Al-, Altaif Kl. The response of Awassi and Merino sheep to primary infection with Haemonchus contortus. Trop Anim Health Prod. 1979; 11:164-70.

40. Almeida FA, Garcia KCOD, Torgerson PR, Amarante AFT. Multiple resistance to anthelmintics by Haemonchus contortus and Trichostrongylus colubriformis in sheep in Brazil. Parasitol Int. 2010;59:622-5.

41. Bautista-Garfias C, Flores-Hernandez O, Quiroz-Romero H. Non-specific resistance of sheep against Haemonchus conforms with Freund's complete adjuvant. Parasite Immunol. 1991;13:565-9.

42. Bricarello PA, Gennari SM, Oliveira-Sequeira TCG, Vaz CMSL, de Gonçalves IG, Echevarria FAM. Response of Corriedale and Crioula Lanada sheep to artificial primary infection with Haemonchus contortus. Vet Res Commun. 2002;26:447-57.

43. Buttle DJ, Behnke JM, Bartley Y, Elsheikha HM, Bartley DJ, Garnett MC, et al. Oral dosing with papaya latex is an effective anthelmintic treatment for sheep infected with Haemonchus contortus. Parasit Vectors. 2011;4:36.

44. Carvalho N, Das Neves JH, Nazato C, Louvandini H, Amarante AFT. The effects of diet and corticosteroid-induced immune suppression during infection by Haemonchus contortus in lambs. Vet Parasitol. 2015;214: 289-94.

45. Christie MG, Angus KW, Hotson IK. Manifestations of resistance to Haemonchus contortus in sheep: Worm populations and abomasal changes in sheep superinfected with 1,000,000 larvae of $H$. contortus. Int J Parasitol. 1975;5:193-8.

46. Chylinski C. What makes a gastrointestinal nematode successful in their sheep host? Exploring the role of the nematode, the sheep host and the farmer. PhD thesis. Tours: I'Université François - Rabelais de Tours; 2014. http://www.theses.fr/2014TOUR4028.

47. Coyne MJ, Smith G. The mortality and fecundity of Haemonchus contortus in parasite-naive and parasite-exposed sheep following single experimental infections. Int J Parasitol. 1992;22:315-25.

48. Cuenca-Verde C, Buendía-Jiménez JA, Valdivia-Anda G, Cuéllar-Ordaz JA, Muñoz-Guzmán MA, Alba-Hurtado F. Decrease in establishment of Haemonchus contortus caused by inoculation of a Taenia hydatigena larvae vesicular concentrate. Vet Parasitol. 2011;177:332-8.

49. De Wolf BM, Zajac AM, Hoffer KA, Sartini BL, Bowdridge S, LaRoith T, et al. The effect of vitamin E supplementation on an experimental Haemonchus contortus infection in lambs. Vet Parasitol. 2014;205:140-9.

50. Galicia-Aguilar HH, Rodríguez-González LA, Capetillo-Leal CM, CámaraSarmiento R, Aguilar-Caballero AJ, Sandoval-Castro CA, et al. Effects of Havardia albicans supplementation on feed consumption and dry matter digestibility of sheep and the biology of Haemonchus contortus. Anim Feed Sci Technol. 2012;176:178-84.

51. Gill HS. Genetic control of acquired resistance to haemonchosis in Merino lambs. Parasite Immunol. 1991;13:617-28.

52. Gill HS, Husband AJ, Watson DL. Localization of immunoglobulin-containing cells in the abomasum of sheep following infection with Haemonchus contortus. Vet Immunol Immunopathol. 1992;31:179-87.

53. González JF, Hernández Á, Molina JM, Fernández A, Raadsma HW, Meeusen ENT, et al. Comparative experimental Haemonchus contortus infection of two sheep breeds native to the Canary Islands. Vet Parasitol. 2008;153:374-8.
54. Hunter AR, Mackenzie G, Ross JG. The effects of transfer factor, parasitic antigen and precipitated immunoglobulin treatments in lambs infected with Haemonchus contortus. Vet Parasitol. 1983;13:45-53.

55. Idris A, Moors E, Budnick C, Herrmann A, Erhardt G, Gauly M. Is the establishment rate and fecundity of Haemonchus contortus related to body or abomasal measurements in sheep? Animal. 2011;5:1276-82.

56. Kassai T, Fésüs L, Hendrikx WML, Takáts C, Fok É, Redl P, et al. Is there a relationship between haemoglobin genotype and the innate resistance to experimental Haemonchus contortus infection in Merino lambs? Vet Parasitol. 1990;37:61-77.

57. Kelkele FA, Tolossa YH, Kassa GM. Experimental infection of Ethiopian highland sheep by different infective doses of Haemonchus contortus (L 3): haematological and parasitological parameters, serum protein concentrations and clinical responses. Ethiop Vet J. 2012;16:41-57.

58. Kerboeuf D. Changes in pepsinogen, proteins and lipids in the serum during experimental haemonchosis in sheep. Ann Rech Vét. 1977;8:257-66.

59. MacKinnon KM, Zajac AM, Kooyman FNJ, Notter DR. Differences in immune parameters are associated with resistance to Haemonchus contortus in Caribbean hair sheep. Parasite Immunol. 2010;32:484-93.

60. Owen NC. Some nutritional aspects of haemonchosis in experimentally infected lambs. South Afr J Anim Sci. 1973;3:1-4.

61. Salle G, Jacquiet P, Gruner L, Cortet J, Sauve C, Prevot F, et al. A genome scan for QTL affecting resistance to Haemonchus contortus in sheep. J Anim Sci. 2012;90:4690-705

62. Salle G, Moreno C, Boitard S, Ruesche J, Tircazes-Secula A, Bouvier F, et al. Functional investigation of a QTL affecting resistance to Haemonchus contortus in sheep. Vet Res. 2014;45:68.

63. Terefe G, Lacroux C, Andreoletti O, Grisez C, Prevot F, Bergeaud JP, et al. Immune response to Haemonchus contortus infection in susceptible (INRA 401) and resistant (Barbados Black Belly) breeds of lambs. Parasite Immunol. 2007;29:415-24.

64. Terefe G, Lacroux C, Prévot F, Grisez C, Bergeaud JP, Bleuart C, et al. Eosinophils in Haemonchus contortus-infected resistant and susceptible breeds of sheep: Abomasal tissue recruitment and in vitro functional state. Vet Parasitol. 2009;165:161-4.

65. Williamson JF, Blair HT, Garrick DJ, Pomroy WE, Douch PGC. The relationship between internal parasite burden, faecal egg count and mucosal mast cells in fleeceweight-selected and control sheep. Proc NZ Soc Anim Prod. 1994; 54:9-14.

66. Yacob HT, Mistre C, Adem AH, Basu AK. Parasitological and clinical responses of lambs experimentally infected with Haemonchus contortus (L3) with and without ivermectin treatment. Vet Parasitol. 2009;166:119-23.

67. Zajac AM, Krakowka S, Herd RP, McClure KE. Experimental Haemonchus contortus infection in three breeds of sheep. Vet Parasitol. 1990;36:221-35.

68. Glass GV, Peckham PD, Sanders JR. Consequences of failure to meet assumptions underlying the fixed effects analyses of variance and covariance. Rev Educ Res. 1972;42:237-88.

69. Jones DR. Meta-analysis: weighing the evidence. Stat Med. 1995;14:137-49.

70. Veglia F. The Anatomy and life history of the Haemonchus contortus (Rud). In: Third and Fourth Reports of the Director of Veterinary Research. Pretoria: Government Printer and Stationery Office; 1915. p. 347-500.

71. Poulin R. Population abundance and sex ratio in dioecious helminth parasites. Oecologia. 1997;111:375-80.

72. Chylinski C, Boag B, Stear MJ, Cattadori IM. Effects of host characteristics and parasite intensity on growth and fecundity of Trichostrongylus retortaeformis infections in rabbits. Parasitology. 2009;136:117-23.

73. Fleming MW. Size of inoculum dose regulates in part worm burdens, fecundity, and lengths in ovine Haemonchus contortus infections. J Parasitol. 1988;6:975-8.

74. Romeo C, Wauters LA, Cauchie S, Martinoli A, Matthysen E, Saino N, et al. Faecal egg counts from field experiment reveal density dependence in helminth fecundity: Strongyloides robustus infecting grey squirrels (Sciurus carolinensis). Parasitol Res. 2014;113:3403-8.

75. Gethings OJ, Sage RB, Leather SR. Density-dependent regulation of fecundity in Syngamus trachea infrapopulations in semi-naturally occurring ring-necked pheasants (Phasianus colchicus) and wild Carrion Crows (Corvus corone). Parasitology. 2016;143:716-22.

76. Stear MJ, Bishop SC, Doligalska M, Duncan JL, Holmes PH, Irvine J, et al. Regulation of egg production, worm burden, worm length and worm fecundity by host responses in sheep infected with Ostertagia circumcincta. Parasite Immunol. 1995;17:643-52. 
77. Paterson S, Viney ME. Host immune responses are necessary for density dependence in nematode infections. Parasitology. 2002;125:283-92.

78. Aumont G, Gruner L, Hostache G. Comparison of the resistance to sympatric and allopatric isolates of Haemonchus contortus of Black Belly sheep in Guadeloupe (FWI) and of INRA 401 sheep in France. Vet Parasitol. 2003;116:139-50.

79. Gruner L, Aumont G, Getachew T, Brunel JC, Pery C, Cognie Y, et al. Experimental infection of Black Belly and INRA 401 straight and crossbred sheep with trichostrongyle nematode parasites. Vet Parasitol. 2003;116:239-49.

80. McRae KM, Good B, Hanrahan JP, Glynn A, O'Connell MJ, Keane OM. Response to Teladorsagia circumcincta infection in Scottish Blackface lambs with divergent phenotypes for nematode resistance. Vet Parasitol. 2014;206:200-7.

81. Stear MJ, Bairden K, Duncan JL, Holmes PH, McKellar QA, Park M, et al. How hosts control worms. Nature. 1997;389:27-27.

82. Cabaret J, Gasnier N, Jacquiet P. Faecal egg counts are representative of digestive-tract strongyle worm burdens in sheep and goats. Parasite. 1998:5:137-42

83. Gilleard JS, Redman E. Genetic diversity and population structure of Haemonchus contortus. Adv Parasitol. 2016:93:31-68.

84. Barger IA, Le Jambre LF. Regulation of Haemonchus contortus populations in sheep: Mortality of established worms. Int J Parasitol. 1988;18:269-73.

\section{Submit your next manuscript to BioMed Central} and we will help you at every step:

- We accept pre-submission inquiries

- Our selector tool helps you to find the most relevant journal

- We provide round the clock customer support

- Convenient online submission

- Thorough peer review

- Inclusion in PubMed and all major indexing services

- Maximum visibility for your research

Submit your manuscript at www.biomedcentral.com/submit 